\title{
Correction to: Morphine-induced supraventricular tachycardia in near-term fetus
}

Vincenzo Zanardo ${ }^{1 *}$, Alphonse Simbi ${ }^{1}$, Matteo Parotto ${ }^{1,2}$, Lorenzo Severino ${ }^{1}$, Riccardo Carta ${ }^{1}$, Pietro Guerrini ${ }^{1}$ and Gianluca Straface ${ }^{1}$

\section{Correction to: Ital J Pediatr https://doi.org/10.1186/s13052-018-0570-1}

The original article [1] contained an error whereby all authors' names were mistakenly inverted. This has now been corrected.

\section{Author details}

'Division of Perinatal Medicine, Policlinico Abano Terme, Piazza Colombo 1, 35031 Abano Terme, Italy. ${ }^{2}$ Department of Anesthesia, University of Toronto, Toronto, ON, Canada.

Received: 24 January 2019 Accepted: 24 January 2019

Published online: 04 February 2019

\section{Reference}

1. Zanardo V, et al. Morphine-induced supraventricular tachycardia in nearterm fetus. Ital J Pediatr. 2018;44:111 https://doi.org/10.1186/s13052-0180570-1.

* Correspondence: vincenzo.zanardo@libero.it

${ }^{1}$ Division of Perinatal Medicine, Policlinico Abano Terme, Piazza Colombo 1,

35031 Abano Terme, Italy

Full list of author information is available at the end of the article 